\title{
REGISTRO ARQUEOLÓGICO REGIONAL CHAQUEÑO
}

\author{
Horacio A. Calandra y Susana A. Salceda
}

\section{Introducción}

La antigüedad del poblamiento original de Sudamérica reviste como un tema de principal importancia en el marco de la problemática arqueológica. Su tratamiento y desarrollo trae aparejado el estudio minucioso de las más recónditas regiones con aplicación de criterios actualizados proponiendo modelos interpretativos y teorías.

No obstante, estas acciones no agotan el desconocimiento que subsiste en ámbitos particulares, como lo representa el Gran Chaco Meridional, donde sólo a partir del desarrollo de investigaciones arqueológicas regionales se logrará caracterizar y categorizar el desarrollo cultural prehispánico.

En el transcurso de la última década, las investigaciones arqueológicas en ese extenso territorio, y especialmente en el sector argentino-chaqueño, se han multiplicado exponencialmente a partir del accionar de grupos de investigación consolidados, situación que ha comenzado a revertir el desconocimiento en que se encontraba sumido.

Tal situación permite, no sólo el planteo de interpretaciones preliminares, sino también el intercambio de opiniones sobre la problemática regional con la integración de temas de investigación no tradicionales en el marco de los estudios arqueológicos. Así, disciplinas vinculadas a las geociencias, desde la paleontología y geología del cuaternario, hasta la hidrología y geotectónica, han provisto con sus planteos un adecuado marco teórico-interpretativo. Ello lleva a vislumbrar jalones cronológicos absolutos y caracteres diagnósticos ajustados (Tonni, 2005) enfatizando en la temporalidad de los procesos de ocupación territorial. Dicha ejecución requirió de la concreción de un proyecto que involucró al Chaco Meridional desde el campo antropológico como su objetivo general y del tema arqueológico en particular.

Durante los últimos años, hemos presentado a consideración de distintos foros científicos, el estado del conocimiento del desarrollo cultural pre y posthispánico del Chaco Meridional (Salceda y Calandra, 2003; Calandra y Salceda, 2004). Tal cual manifestáramos, el mismo se substanció en los datos proporcionados por investigadores que nos precedieron y desde la información aportada por nuestros propios estudios, dilucidando las incógnitas, ya sea en la propia área como en territorios circundantes.

Esta presentación es una actualización de la arqueología chaqueña, que incrementa constantemente su corpus contextual mediante investigaciones de campo continuas, generadoras de apreciaciones e interrogantes que fundamentan la necesidad de dar continuidad a los estudios regionales.

En esta etapa nos hemos propuesto establecer un panorama general, fundamentalmente a partir de un reconocimiento espacial detallado, priorizando las investigaciones extensivas por sobre las intensivas y localizadas, en función de la vasta 
territorialidad. No obstante, en aquellos sitios que por su caracterización lo justifican se desarrollaron y desarrollan excavaciones minuciosas ("El Cachapé" SChaPrim 4-1, SChaPrim 4-2; "Puesto Fantín" SChaSaf 40-1, "Las Bolivianas" SForBer 2-2) produciendo información vital y ordenada.

También en estos últimos tiempos otros dos aspectos se integraron o han tomado mayor significación. Por un lado el corpus etnográfico que, no obstante su abundancia y riqueza, aún no manifiesta conexión tácita con el pasado prehispánico y, por lo tanto, no alcanza para explicar el proceso cultural acontecido. Sin embargo su esencial aporte metodológico en el diseño de las investigaciones en el área ha facilitado enormemente la interpretación de los asentamientos humanos en la sectorización ecológico-cultural propuesta (Braunstein et al., 2002)

El otro aspecto, de fundamental interés, consiste en dirimir el papel que le cupo a esta región como escenario del derrotero de primigenios grupos poblacionales, es decir su ocupación temprana, y su ulterior dinámica. Aquí, la información brindada por la Bioantropología, a partir del análisis de similitudes morfológicas y morfométricas en poblaciones extintas, así como, estudios genéticos con correlato geográfico-lingüístico, en una aproximación válida que incursiona en el pasado desde un presente sistematizado por la etnografía y la etnolingüística, ha producido avances significativos en la última década (Braunstein et al, op. cit.; Calandra y Salceda, op. cit.).

En este marco y en el estado del conocimiento regional en el que nos encontramos, sería precipitado arriesgar opiniones terminantes que califiquen de ausentes, a niveles de ocupación correspondientes, a los más antiguos paleoamericanos. Desconocemos la presencia de registro identitario de ellos y aún de aquellos que pudieran haber vivido en el Chaco durante la transición pleistoceno-holoceno. Implica opinión la ausencia generalizada de rasgos, conjuntos o aislados, aún en colecciones museológicas o referencias bibliográficas. Acaso la posibilidad de su previsible existencia surja a partir de la presencia de canteras cuarcíticas (afloramientos regionales únicos) en el sector central, en zona de contacto entre las provincias del Chaco y Santiago del Estero. Deberíamos considerar a esta zona proveedora de materia prima lítica, un sector expectable de hallazgo de evidencias. Allí la búsqueda exhaustiva, si bien aun no proporciona datos determinantes, las evidencias de fauna extinta, las canteras líticas y los paleocauces motivan la intensificación de las investigaciones con la aplicación de estrategias, interpretaciones y excavaciones ajustadas a este nuevo planteo temático. Esa distribución puntual de materia prima lítica dentro de un territorio tan extenso, facilita la pesquisa aunque reconocemos que la distancia que separa cualquier punto del Chaco Meridional de otros afloramientos de roca en territorios periféricos, no puede haber sido impedimento para su obtención. De todos modos y durante nuestro tiempo de trabajo en el área, nunca hemos hallado material lítico en relación contextual con restos arqueológicos. La presencia esporádica de hachas de piedra pulida, producto de hallazgos fortuitos, constituye un elemento foráneo y relativamente reciente. En un medio en el cual la madera y el hueso representan una materia prima dúctil para su instrumentación, consideración sugerida por la observación analógica, es válido contemplar su uso en la 
confección de útiles, y esta resolución sí tiene precedentes en hallazgos realizados en sitios arqueológicos cronologizados en el 700 de nuestra era en áreas periféricas.

En un marco generalizador acorde con el estado actual del conocimiento y a los registros cronológicos absolutos disponibles, debería considerarse que las primeras ocupaciones del Chaco Meridional orillan entre el 200 y el 700 de nuestra era. Este extenso territorio fue recorrido intensamente por los primeros españoles que se internaron "tierra adentro". De su paso y trayectoria existen numerosas evidencias que dan identidad al período comprendido entre los siglos XVI y XIX, tiempos durante los cuales se asentaron numerosas instalaciones coloniales (Tomasini y Calandra, 1999) relacionadas a asentamientos aborígenes. Estos primeros expedicionarios en arribar al territorio comienzan a producir información escrita, que se enriquece notoriamente a comienzos de la campaña evangelizadora. Ello posibilitó la caracterización de los distintos grupos aborígenes, produciendo un sustrato informativo sobre el cual, aún hoy, los investigadores de ese campo plantean sus hipótesis. No cabe duda entonces que, al tiempo del contacto hispano-indígena, la región representaba un espacio geográfico alojando una significativa cantidad de grupos étnicos, en muchos casos con proyección territorial hacia ámbitos periféricos.

\section{El escenario ambiental}

El Chaco está incluído en una de las regiones más extensas de Latinoamérica, la Neotropical, dentro de la cual, el Dominio Chaqueño se caracteriza por su clima continental, con lluvias medias a bajas, concentradas en primavera y verano, con inviernos suaves y veranos cálidos. En el marco de este Dominio, y desde nuestro especial interés, reconocemos a la Provincia Chaqueña con similares características generales y en relación con la Llanura Chaco-Pampeana, la más extensa de Sudamérica (Cabrera y Willink, 1973). La constitución general de los suelos refleja una llanura sedimentológica. Las irregularidades del terreno, producto de la presencia de relieves positivos y negativos de escasa altitud y profundidad, albergan lagunas de distinta magnitud y numerosos cursos de agua que almacenan o atraviesan el territorio con una escasa pendiente en sentido noroeste sudeste. La consecuente indecisión de la red fluvial es la causal determinante de la presencia de numerosos cursos abandonados (Morello y Adámoli, 1974).

Estas principalísimas características ambientales, su relativa estabilidad en los últimos 10000 años (Iriondo, 2005), y la rica biodiversidad presente hacen presumir, con no arriesgada certeza, la cualidad de "habitable" que ha tenido y tiene el Chaco.

Respecto a esta habitabilidad y sus determinantes (aspectos climáticos, comportamiento hidrológico, caracterización botánica y zoológica, otros), el Gran Chaco revela una excelente potencialidad sustentadora y capacidad para un desarrollo sostenible en función de los indicadores existentes y de la respuesta interactiva (hombre-medio ambiente) que la actitud humana generare. El hecho de subsistir en el ámbito, histórica y actualmente, grupos etnográficos y criollos con formas de vida en estrecha dependencia con el medioambiente, facilita enormemente la identificación y evaluación de las posibles formas de apropiación y dimensión del consumo en general en tiempos pasados. Este análisis 
y el propio etnohistórico, llevan a considerar la existencia, hacia el momento del contacto hispano indígena, de poblaciones humanas numerosas habitando la región. Por lo tanto, y para los tempranos tiempos prehispánicos, no existe evidencia determinante de ninguna índole (cultural, ecológica, climática) que permita inferir impedimento alguno para la presencia de grupos humanos en la región.

\section{Ubicación geográfica del Gran Chaco \\ Geographische Lage des Gran Chaco \\ (Fuente/Quelle: GTZ 1996, kanter 1936, Morello 1983)}

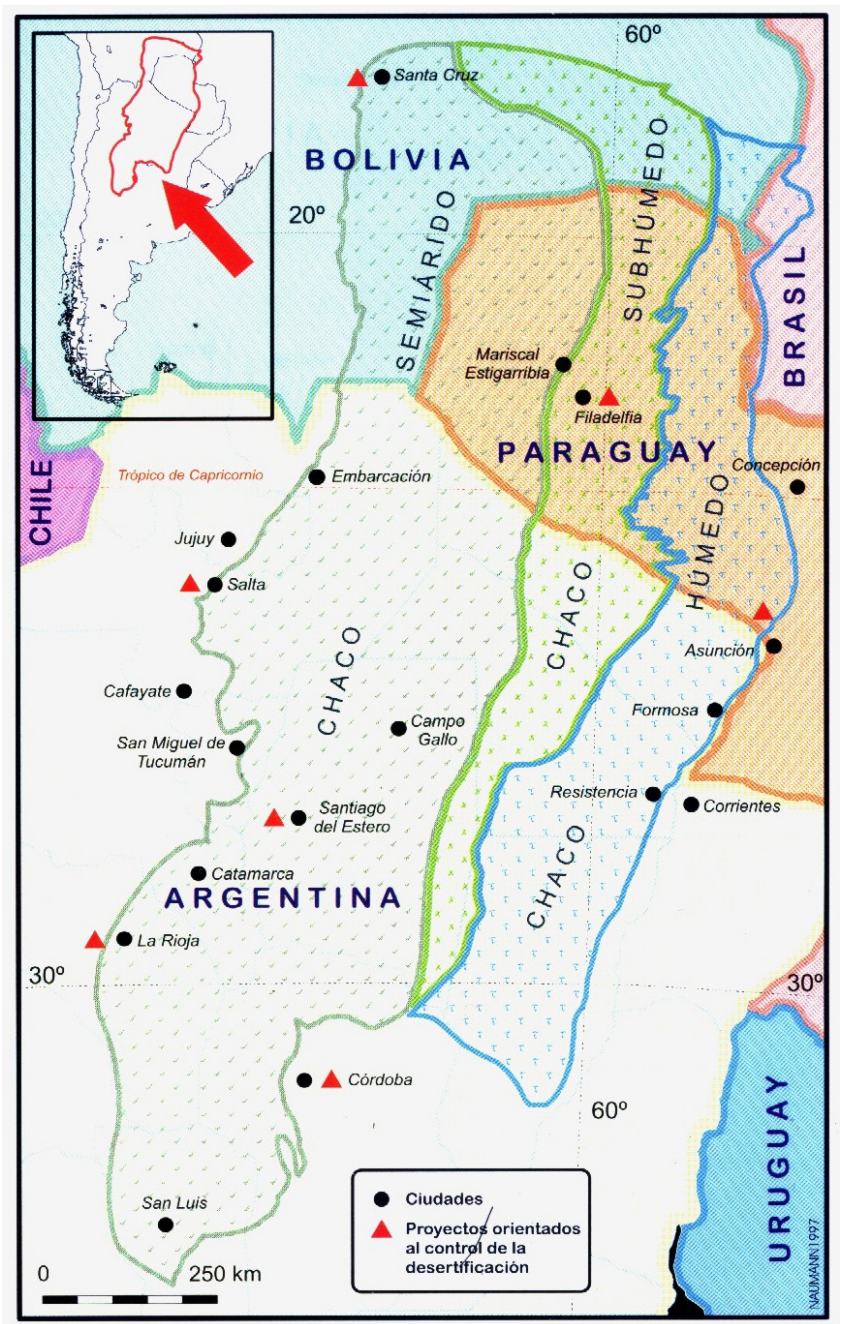


El dato arqueológico y el etnográfico refieren a estos grupos como de disposición dispersa y móvil, con estacionalidad fluctuante en relación con los niveles de inundación del terreno, paradigma que parece haber sido eficaz hasta el siglo XIX, tiempos coincidentes con la conformación del estado nacional. En la zona ribereña del sistema Paraná Paraguay, este modelo aun perdura con una modalidad de instalación que abarca la ocupación de las líneas de costa del gran Paraná hasta los niveles de terraza de mayor altura, coincidentes con el trazo de la actual ruta nacional $\mathrm{N}^{\circ} 11$, nivel que representa el resguardo seguro en tiempos de máxima inundación. Arqueológicamente esta relación no está determinada fehacientemente, aunque los asentamientos localizados y su correspondencia ergológica, evidencian lo tradicional del modelo.

Hoy el Chaco, aún conformando un espacio de equilibrio ecológico inestable donde las oscilaciones climáticas y el abuso antropogénico representan disparadores de alteración, cubre las necesidades básicas de las poblaciones nativas y criollas con marcada dependencia del sistema ecológico. En este punto cabe remarcar que regionalmente ha tomado significación catastrófica el quehacer calificado como "agrobusiness" el cual arrolla despiadadamente al interés ecológico-cultural. Así, y en el ritmo vertiginoso en que se desarrolla el manejo agropecuario, la investigación arqueológica adquiere el carácter de salvataje.

\section{Sectorización ecológico-cultural}

Este amplio territorio que denominamos Chaco Meridional, con condiciones tan particulares, ha sido segmentado para su mejor estudio utilizando, fundamentalmente, criterios biogeográficos y culturales (Braunstein et al, 2002), habiéndose definido tres sectores amplios para los cuales se sistematizaron los datos éditos e inéditos, en concordancia con normas establecidas y explícitas convenidas en reuniones de trabajo entre especialistas (Primera Convención Nacional de Antropología - Primera Parte -, 1966; Tarrago y Núñez Regueiro, 1972; Calandra y Dougherty, 1991).

Dicha segmentación requirió de un paso posterior en el cual se localizaron y caracterizaron culturalmente todos los sitios arqueológicos registrados hasta el año 2001. Sobre un total de 100 yacimientos, 37 corresponden al Sector Central, 14 al Sector Subandino Chaqueño y 49 al Ribereño Paraguay-Paraná (De Feo et al, 2002). En términos generales, las investigaciones arqueológicas tuvieron mayor desarrollo en estos dos últimos sectores, independientemente del número de sitios reportados. El Sector Central ha sido el menos trabajado en todas sus latitudes, sólo el subsector sudoeste provee mayores aportes, debido fundamentalmente a la existencia, en la localidad de Charata (Pcia. de Chaco) de un Museo Municipal de Ciencias Naturales que nuclea a personal calificado e inquieto por la temática arqueológica. El mayor cúmulo de información sobre el oeste (Sector Subandino Chaqueño), es reflejo del énfasis dado a la investigación en un territorio marginal del área andina, especialmente de los ámbitos Valliserrano y de Selvas Occidentales. Del mismo modo el este chaqueño, limitado por el curso Paraguay Paraná, aporta gran cantidad de datos, tal vez por el papel preponderante que juega su emplazamiento cartográfico, en zonas en 
que la existencia de fuertes intervenciones sobre el medio natural con ponderable impacto ambiental, exponen frecuentemente el subsuelo y, por ende, su contenido arqueológico.

\section{Los asentamientos y el aprovechamiento de los recursos}

En general y más allá de sus variaciones locales, los sitios de asentamiento se encuentran emplazados en relación a cursos de agua o lagunas sobre alturas manifiestas, generalmente albardones ribereños. Su extensión varía en función del espacio disponible y de la cantidad y calidad de recursos existentes, factor condicionante de la actividad que desarrolla el grupo humano allí asentado.

Se han podido individualizar sitios uni y biocupacionales de escasa potencialidad estratigráfica. Su finalidad (permanente, estacional, aprovisionamiento, de paso, otras) está en relación directa con la variación de los factores limitantes (agua, recursos alimenticios) cuya resolución diferencial por sector implica el tiempo de permanencia en los sitios. En este punto, la delimitación del ámbito vecinal y regional, en cuanto a sus condiciones como zonas de caza, pesca, recolección y de obtención de materias primas para la confección de útiles, adquiere especial significación.

Interpretando estos aspectos desde cada uno de los sectores, en la zona de influencia del Paraguay-Paraná, los sitios aparecen como de carácter unifamiliar, con distribución dispersa conformando con otros de resolución similar, emplazados a más de $2 \mathrm{~km}$ de distancia, asentamientos sobre albardones condicionados, en su tiempo de ocupación, al factor limitante agua, ya que en este sector los mínimos inundables alcanzan la cota de los emplazamientos habituales. Los recursos animales tienen fuerte representación en el registro arqueológico.

En el sector central, y siempre en relación con el agua, las superficies de ocupación son más amplias, conformando un núcleo de instalaciones dispersas que, conjuntamente con su estratigrafía, evidencian una mayor estabilidad. El dato arqueofaunístico relevado no refleja énfasis en su uso. Ambas características, estabilidad y escasa fauna en el registro, habilitan la posibilidad de horticultura como actividad complementaria y, de hecho, el dato etnohistórico y etnográfico refuerzan esta inferencia jerarquizando, además, el papel preponderante de la recolección en el sistema económico de estos grupos. En general, el ambiente en este sector restringe la representación numérica de especies animales estando las presentes dispersas en tiempo de agua y concentradas en espacios precisos y localizados el resto del año.

En el sector subandino, la modalidad de asentamiento indica presencia de poblaciones semisedentarias de pocos individuos, con pautas económicas y sociales diversas en relación con las asignaciones cronológicas (Dougherty, 1974). Debe remarcarse que este ámbito refleja idiosincrasias culturales representativas de un sincretismo entre las tierras altas y las tierras bajas. Así, la presencia en las laderas orientales subandinas de recintos con paredes de piedra, aunque con menor frecuencia, es indicativa de influencia andina, en tanto que las mayoritarias viviendas construidas con materiales perecibles (ramas y barro amasado) constituyen un rasgo identitario común para el territorio del gran Chaco. También la diversificación económica caracteriza en tiempo y espacio al sector subandino chaqueño. La información producida por distintos investigadores remarca esta opinión 
(Nordenskiöld, 1903; Dougherty, op. cit.). El corpus arqueológico artefactual asigna la presencia de elementos vinculados a la molienda, hachas líticas y piezas cerámicas provenientes de otros ámbitos vecinos (Región Valliserrana) donde la agricultura alcanza desarrollo pleno. Del mismo modo, el manejo de animales domésticos debe considerarse como una opción posible pues el registro arqueológico verifica presencia de piezas óseas articuladas así como de las actividades de caza, pesca y recolección.

Así, la cantidad de asentamientos humanos detectados, aun con lo relativamente incipiente de las investigaciones arqueológicas en esta amplia región, parece concordar con aquellas posturas teóricas que, oponiéndose a la falacia del modelo explicativo determinista ambiental, en cuanto a reducir al ser humano a un "....mero subproducto de condiciones ambientales..." (Funari y Noelli, 2002) degenerativas de la cultura, lo sitúan en una región con riqueza ambiental, que le permite desarrollar estrategias alternativas y diferenciales en cuanto a la apropiación de recursos en un medio ambiente diverso.

\section{La funebria}

El registro inhumatorio del Chaco Meridional refleja una variada gama de comportamientos ante la muerte, derivados de la concepción que los grupos humanos tienen de ella y refiriendo a aspectos vinculados con su plano ideológico.

Las variadas formas inhumatorias registradas han sido siempre descriptas e interpretadas en función de influencias de grupos humanos de ámbitos periféricos (amazónicos o andinos). Hoy, el dato arqueológico aporta información que permite inferir la utilización de prácticas regionales propias, que en determinadas situaciones rebasan el territorio chaqueño y de otras con reminiscencias geográficamente lejanas.

En el orden regional el ítem funebria tiene su mejor documentación en el sector subandino chaqueño. Descripciones minuciosas de formas de inhumación como la de párvulos y adultos directamente en tierra han sido hechas ya desde principios del siglo XX (Boman, 1903; Nordenskiöld, 1903). En 1960 N. Fock aportó información sobre excavaciones y hallazgos realizados en el antiguo curso del río Bermejo o Teuco (Fock, $1960 ; 1966)$. Describe enterratorios en las modalidades de adulto en urna, niño en urna y adulto y niño en urna, así como adulto directo en tierra. Fock hace explícita referencia a la procedencia de la modalidad inhumatoria en urna y concluye acordando con el criterio de Boman en cuanto al origen guaraní de la misma, aunque prefiere asignarla a grupos preguaraní. Del mismo modo hace referencia a la adscripción de la modalidad secundaria de inhumación, atribuyéndole un origen más antiguo y propio del este, comentando su presencia en el área Amazónica y hasta el delta del río Paraná. Además, regionalmente y dentro del marco del complejo cultural San Francisco, se incluyen otros sitios con descripciones que involucran resoluciones similares a las ya citadas. Sólo el sitio El Talar, excavado por Menghín y Laguzzi, en las proximidades de la Estación Urundel en la provincia de Salta, presenta una modalidad innovadora de adulto en urna, colocado secundariamente, con cremación parcial y con superficies pintadas con ocre rojo. 
Para el Sector Central, en territorio de la provincia del Chaco, en el paraje San Bernardo El Vértiz, se registraron inhumaciones de adultos directas en tierra (Salceda y Calandra, 2003). En esta misma provincia, próximo a Frías, en el cauce del Teuco, se documenta el hallazgo de entierros secundarios en urna conteniendo restos óseos en muy mal estado de conservación (Tobisch, 2003 informe inédito). Al norte del actual curso del Bermejo, próximo a la localidad de Pozo del Mortero, Laguna Yema y Las Lomitas, también se han reportado hallazgos de entierros secundarios en urna y en este último paraje de adultos directos en tierra en distintos puntos.

Por último, en el Sector Ribereño Paraguay-Paraná, en latitud correspondiente a la zona de contacto de esos dos grandes ríos, se ha registrado la presencia de adultos directos en tierra, criterio que se repite y documenta en las proximidades de Resistencia y, más recientemente de párvulo directo en tierra (Desántolo et al., 2005). Es de remarcar aquí la presencia de curiosos hallazgos que revelan selección de partes esqueletarias y hasta señalización de su ubicación en el espacio de vivienda doméstica, lo cual alerta sobre una posible práctica identificada en otros lugares como ofrendas de fundación.

En general, es escaso el uso de piezas cerámicas especialmente confeccionadas con fines funerarios. En la mayoría de los enterratorios en urna, las vasijas utilizadas en actividades domésticas fueron reutilizadas como contenedoras de restos óseos y así lo refieren diversos autores (Canals Frau, 1965; Palavecino, 1944).

En síntesis, las modalidades funerarias arqueológicas registradas hasta el momento en el territorio chaqueño son: entierros directos en tierra de adultos y/o subadultos, entierros de adulto en urna, párvulo en urna o adulto y párvulo en urna, primarios o secundarios, en posiciones diversas. En general las inhumaciones directas en tierra se ubican en los mismos sitos de habitación o estructuras vinculadas a ellos. Los hallazgos de urnas únicos o múltiples, no se corresponden con habitaciones o estructuras vinculadas. Las frecuencias de ambos tipos de modalidades (directo en tierra - urna) es similar para el territorio con una distribución diferencial entre sectores. Mientras que en el Ribereño Paraguay-Paraná sólo se han registrado entierros directos, en los sectores Central y Subandino han sido detectadas ambas modalidades, con mayor representación del entierro en urna en su franja norte regional. Si esta modalidad se relaciona con grupos guaraní o preguaraní, su influencia en ámbito chaqueño necesariamente debe haber sido de norte a sur utilizando la vía subandina oriental, zona de penetración donde hallazgos esporádicos jalonan este hecho. Refuerza esta opinión la ausencia de elementos decorativos guaraní en el ítem cerámico del Sector Ribereño. Los hallazgos de partes esqueletarias en basurales, así como la señalización de los lugares de entierro nos hablan de una compleja posición ante la muerte.

\section{La cerámica}

El ítem cerámico representa, como ya dijéramos reiteradamente, uno de los más significativos indicadores arqueológicos regionales, fundamentalmente por su frecuencia de hallazgo y perdurabilidad. Su caracterización minuciosa, evidencia una singularidad que permite reconocerlo como de "origen chaqueño". 
El ordenamiento cerámico se realizó sobre el total de la muestra conocida que representa una colección de aproximadamente 10.000 fragmentos, diagramado con la finalidad de caracterizar conjuntos, establecer frecuencias, dispersión y correlaciones, conformando identidades útiles para servir como indicadores diagnósticos.

Los resultados de estos procedimientos determinaron la existencia de conjuntos decorados de representación mayoritaria designados como corrugado e inciso (Lamenza et al, 2005), ambos agrupando variantes, y reconocida presencia de las alfarerías decoradas con filete aplicado (Calandra et al, 2001), impresión de cordelería (Calandra et al, 2002) y pintura post cocción de color rojo.

En términos generales se entrevé un nexo morfo-decorativo entre la alfarería chaqueña y otros conjuntos alfareros descriptos para la periferia regional. Hacia el este la relación incluye a las denominadas Tradiciones Planáltica, Sabanas Bajas y Ribereña Paranaense (Rodríguez, 1992). Si bien las valoraciones cronológicas para estas tradiciones sobrepasan la profundidad temporal asignada hasta el momento a la alfarería chaqueña, rasgos morfológicos y decorativos señalan reminiscencias, reforzadas por similitudes en otros aspectos ecológico-culturales.

Hacia el oeste, en ámbitos subandinos, la relación se establece de manera directa con las culturas San Francisco, Candelaria y El Arasayal (Dougherty, 1974; Heredia, 1970; Dougherty et al, 1978), la primera de ellas de manifestación neta en Lomas de Olmedo (Chaco Salteño), la segunda con clara presencia en Pampa Grande, a nuestro juicio un énclave chaqueño en ámbitos valliserranos y El Arasayal en las proximidades de Orán a orillas del Río Pescado, caracterizado por cerámica incisa, pintada, corrugado, filete aplicado y de morfología subglobular.

La zona septentrional del Gran Chaco (Gran Pantanal al sur), territorio con menor información, representa a su vez la mejor posibilidad y la mayor incógnita para explicar rasgos andinos en ámbitos chaqueños. La vertiente oriental andina regional en sus distintas latitudes, fundamentalmente al norte, acumula importante información al respecto dando sentido significativo al criterio de flujo y reflujo de bienes chaqueños en los andes y viceversa. Visto desde las tierras bajas estas latitudes tan septentrionales respecto del actual chaco argentino, el Chaco boliviano paraguayo, suponemos que han sido el ámbito propicio para estos movimientos fluctuantes entre territorios amazónicos y subandinos orientales. Así, la documentación arqueológica y su interpretación más reciente refuerzan los fundamentos para reafirmar el área geográfico-cultural Pedemontana (Nuñez Regueiro y Tartusi, 1987) que se extiende hacia el sur, apoyándose en subandinas orientales constituyendo un área significativa de desarrollo cultural a la cual debería referirse la totalidad de la interrelación tierras altas - tierras bajas que ocurre en el área andina meridional y fundamentalmente ceñida al ámbito serrano.

$\mathrm{A} 1$ sur, más allá del paralelo $31^{\circ}$, en el área arqueológica pampeana, y como resultado de investigaciones intensivas desarrolladas por más de 100 años, destacándose la sistematización más reciente de abordajes multidisciplinarios, con énfasis en estudios bioestratigráficos, se plantean ordenamientos espaciales precisos algunos de los cuales 
manifiestan relaciones más estrechas con el Chaco meridional, es decir con su límite norte. El uso de la alfarería facilita esta vinculación, no existiendo a la fecha valores cronológicos y culturales que distingan nexos en tiempos previos, no por diferenciaciones en las representaciones de los instrumentos y modalidades de ocupación sino, simplemente, por la ausencia de ellos. Paraná mediante entramos en su hábitat y la presencia de estos cazadores recolectores más antiguos se encuentra desde allí hacia el sur con continuidad tomando el espacio pampeano que en sus áreas norte, noreste y depresión del Salado del sur, muestra secuencias en desarrollo, casi continuas, en las cuales, en su segmento más reciente, es donde se manifiesta la cerámica lisa e incisa geométrica vinculante con la región chaqueña más meridional.

Un párrafo en especial debemos agregar respecto a ciertas particularidades de la cerámica decorada chaqueña. En el Sector Ribereño del Chaco argentino, la decoración incisa de surco rítmico y la punteada sobre el labio característica de la zona sur de la confluencia Paraná-Paraguay, se diferencia significativamente de los conjuntos cerámicos al norte de la confluencia, caracterizados por la cerámica corrugada y sus variantes. Las características ambientales compartidas y las similitudes de los fechados radiocarbónicos ${ }^{1}$ de ambas zonas demuestran que las diferencias estilísticas mencionadas no se deben a cuestiones temporales ni a adaptaciones diferenciales, sino que podrían deberse a que estén funcionando otro tipo de agentes, tal vez, motivaciones ideológicas y/o políticas. Probablemente a través de la cerámica estos grupos han transmitido la información codificada que reproduce la naturaleza de las relaciones intra e intergrupales, reafirmando, por un lado, el conjunto de comportamiento esperado para con los miembros del mismo grupo y, por otro, como forma de demarcación territorial y diferenciación con los otros.

En el Sector Central, en la zona limítrofe con la provincia de Santiago del Estero, la alfarería presenta decoración pintada pre-cocción, rasgo que vinculado al tipo de asentamiento -con almacenamiento intencional de agua- $y$ la propia vecindad con la cultura chacosantiagueña, sugieren vinculaciones, aunque tenues.

En suma y para finalizar, el conjunto de datos aludidos, aún con certeza sólo aproximativa, permiten considerar el arribo al Chaco de un grupo precursor, en fechas cercanas al inicio de la era cristiana, portador de conjuntos cerámicos (incisos, pintados, corrugados, modelados, entre otros) representativos de modalidades presentes en Tierras Bajas, en ámbitos más septentrionales que el noroeste argentino, desplazándose de norte a sur vía las serranías subandinas y ocupando sólo la zona de transición que denominamos Sector Subandino Chaqueño.

Recién a partir del 500 D.C. comienzan a manifestarse nuevos caracteres cerámicos (corrugados, corrugados incisos, pintura post cocción, cordelería impresa, filete aplicado) dispersos espacial y temporalmente en todo el ámbito chaqueño, aunque mostrando diferenciaciones regionales fundamentalmente en relación con particularidades

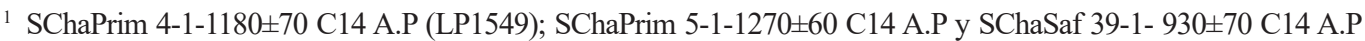
(LP1566).
} 
morfológicas y decorativas y con existencia de entidades cerámicas bien caracterizadas tales como la Tradición Ribereña Paranaense y De Las Llanuras Centrales (Rodríguez, 2005; Ceruti, 1998).

\section{Bibliografía}

Boman, E. 1903. "Enterratorio prehistórico en Arroyo del Medio (Departamento Santa Bárbara, Jujuy)". Historia, 1. Buenos Aires.

Braunstein J.A., S.A. Salceda, H.A. Calandra, M.G. Méndez, S.O. Ferrarini, 2002. "Historia de los chaqueños - Buscando en la "papelera de reciclaje" de la antropología sudamericana". Acta Americana, Journal of de Swedish Americanist Society. Vol. 10 (1): 59-88. Suecia.

Cabrera A. y Willink A., 1973. Biogeografía de América Latina. Monografía No 13. Serie de Biología. OEA. Washington.

Calandra H. y Dougherty B., 1991. "Prospección arqueológica en la Provincia de Formosa, República Argentina”. Hacia una Nueva Carta Étnica del Gran Chaco, pp 133-141.

Calandra H., S.O. Ferrarini, M. Santini, 2001. “Alfarería vinculante entre Selvas Occidentales y Chaco Meridional”. Milenio, pp 117-120.

Calandra H., S.A. Salceda, M. Cid de la Paz, O. González, M. Caló, 2002. “Arqueología Chaqueña 3: Nuevas evidencias de cordelería impresa”. Actas del XXII Encuentro de Geohistoria Regional, pp 72-76. Resistencia, Chaco.

Calandra H. y Salceda S.A., 2004. "El territorio y sus ocupantes:¿qué, quienes, cómo y cuándo?”. FOLIA Histórica del Nordeste Nº15: 107-128. Resistencia, Chaco.

Canals Frau S., 1965. Las poblaciones indígenas de la Argentina. Su origen, su pasado, su presente. Ed. Sudamericana, Buenos Aires.

Ceruti C., 1998. "La Tradición de las Llanuras Centrales". En: Homenaje Alberto Rex González. FADA. Universidad de Buenos Aires.

Desántolo B., Santini M., Salceda S.A., 2005. “Arqueología chaqueña 4: hallazgo de restos óseos humanos en el sitio arqueológico "El Cachapé Potrero V” (Pcia. de Chaco). Informe preliminar". Actas del XXV Encuentro de Geohistoria Regional. IIGHI-CONICET. Corrientes. CDrom, formato libro.

De Feo C., Calandra H., Salceda S., Santini M., Aguirre B., Lamenza G., Lanciotti M., Del Papa L., Porterie A., 2002. "Localización espacial y caracterización cultural de sitios arqueológicos del Gran Chaco meridional". Actas del XXII Encuentro de Geohistoria Regional, pp 121-134. Resistencia, Chaco.

Dougherty B., 1974. Nuevos aportes para el conocimiento del Complejo Arqueológico San Francisco (Sector septentrional de la Región de las Selvas Occidentales, subárea del Noroeste Argentino). Tesis Doctoral. Facultad de Ciencias Naturales y Museo. Universidad Nacional de La Plata.

Dougherty B., Calandra H., Crowder R., 1978. "Arqueología de las selvas occidentales del norte". SAPIENS N²: 40-50.

Fock N., 1961. "Inca Imperialism and Chaco Burial Forms”. En Folk, 3. Kobenhavn.

Fock N., 1966. "Chaco Pottery and Chaco History, Past and Present”. Akten des 34. Internationales Amerikanisten Kongresses: 477-484. Wien.

Funari P.P. y Noelli F.S., 2002. Prè-Historia do Brasil. Repensando a Historia. Ed. Contexto. São Paulo. Heredia O.R., 1970. Investigaciones arqueológicas en el sector meridional de la Subárea de las Selvas 
Occidentales. Tesis Doctoral. Facultad de Filosofía y Humanidades. Universidad Nacional de Córdoba.

Iriondo M., 2005. "Cambios ambientales en el Chaco argentino y boliviano en los últimos miles de años". FOLIA Histórica del Nordeste $\mathrm{N}^{\circ} 16$. Resistencia, Chaco.

Lamenza G., Aguirre B., Calandra H., 2005. “Alfarería arqueológica del Sector Paraguay Paraná del Chaco Meridional: su sistematización e identidad”. Actas del XXV Encuentro de Geohistoria Regional. IIGHI-CONICET. Corrientes. CDrom, formato libro.

Morello J. y Adámoli J., 1974. La vegetación de la República Argentina. Las grandes unidades de vegetación y ambiente del Chaco argentino. INTA. Serie Fitogeografía No ${ }^{\circ} 3$. Buenos Aires.

Nordenskiöld E., 1903. "Präecolumbische Wohn-und Begrabnisplatze an der Süd-Westgrenze von Chaco”. Kungl. Suenska Vetenskaps Akad. Handlingär, 36 (7). Stockholm.

Nuñez Regueiro V. y Tartusi M., 1987. “Aproximación al estudio del Area Pedemontana Sudamericana”. Cuadernos del Instituto Nacional de Antropología, 12:125-160. Buenos Aires.

Palavecino E., 1944. "Prácticas funerarias norteñas: Las de los indios del Chaco". Relaciones IV. Buenos Aires.

Primera Convención Nacional de Antropología - Primera Parte, 1966. Instituto de Antropología. Facultad de Filosofía y Humanidades. Universidad Nacional de Córdoba.

Rodríguez J.A., 1992. “Arqueología del Sudeste de Sudamérica”. En Prehistoria Sudamericana: nuevas perspectivas. B.J. Meggers (ed). Pp: 177-209. Washington D.C.

Rodríguez J.A., 2005. "El doblamiento y el proceso de la secuencia cultural prehistórica de la cuenca del Plata". FOLIA Histórica del Nordeste Nº16. Resistencia, Chaco.

Salceda S.A. y Calandra H.A., 2003. La planicie chaqueña: orígenes de su historia. Duodécimo Congreso Nacional y Regional de Historia Argentina. Academia Nacional de la Historia. Pp: 1-18. Buenos Aires.

Tarragó M., y Núñez Regueiro V., 1972. "Un diseño de Investigación Arqueológica para el Valle Calchaquí. Fase exploratoria”. Estudios de Arqueología No1:62-85. Museo Arqueológico de Cachi, Salta.

Tobisch A., 2003. Informe inédito de las actividades realizadas en el marco del proyecto "De las historias étnicas a la prehistoria en el Gran Chaco argentino".

Tomasini A., Calandra H.A., 1999. "La arqueología histórica del extremo S.W. del Gran Chaco. Estudio preliminar". FOLIA Histórica del Nordeste, Nº14: 33-62. Resistencia, Chaco.

Tonni E.P., 2005. "Cambio climático en el Holoceno Tardío de la Argentina. Una síntesis con énfasis en los últimos 1000 años”. FOLIA Histórica del Nordeste Nº16. Resistencia, Chaco.

\section{Resumen}

Esta presentación plantea una actualización del estado de conocimiento del poblamiento prehispánico del Chaco Meridional. Indicadores culturales y bioarqueológicos se complementan con otros procedentes del campo de las geociencias, comprobándose la ocupación regional desde los comienzos de nuestra era. La movilidad de las poblaciones y su modalidad de asentamiento y explotación de determinados ambientes componen rasgos caracterizantes que permiten distinguir a los cazadores-recolectores chaqueños otorgándole al ámbito particularidades que quizás compongan una entidad propia y diferenciada de su periferia.

$<$ Llanura chaqueña $><$ HolocenoTardío $><$ arqueología $>$ 
Folia Histórica del Nordeste, No 16 (Resistencia, 2006) IIGHI, CONICET - IH, UNNE)

\begin{abstract}
This paper presents an update of the information about the prehispanic population of southern Chaco. Cultural and bio-archaeological indicators and other indicators from the geosciences complement one another proving regional occupation since the beginning of our era. The mobility of the populations and their settling pattern and exploitation of certain environments constitute characterizing features that help us recognize hunter-gatherers from Chaco providing special characteristics to the field that might constitute an entity in themselves and differentiate it from its periphery.
\end{abstract}

$<$ Chaco plains $><$ Late Holocene $><$ Archaeology $>$ 